\title{
Invisible Ink
}

\author{
Abigail Ralph \\ University of Toronto Scarborough \\ Faculty of Biological Sciences; Neuroscience, Health Policy and Psychology
}

\section{A B S T R A C T}

There is a gap in academic literature that highlights the perspectives of Canadian-Caribbean individuals that navigate both poverty and the stigma of limited access to resources necessary for livelihood in Canada. By employing the intersecting identities of Low-Income and (un)documentation, this poem aims to deconstruct the stereotypical expectations of Canadian-Caribbean immigrants. What does an impoverished Canadian-Caribbean immigrant look like once we've disregarded our representativeness heuristic? They now may be the straight-A student in your class or that lady that never seems to wear an uncoordinated outfit - or perhaps your lecturer or community organizer who has an undying passion for 19th-century opera. By mobilizing this idea, this

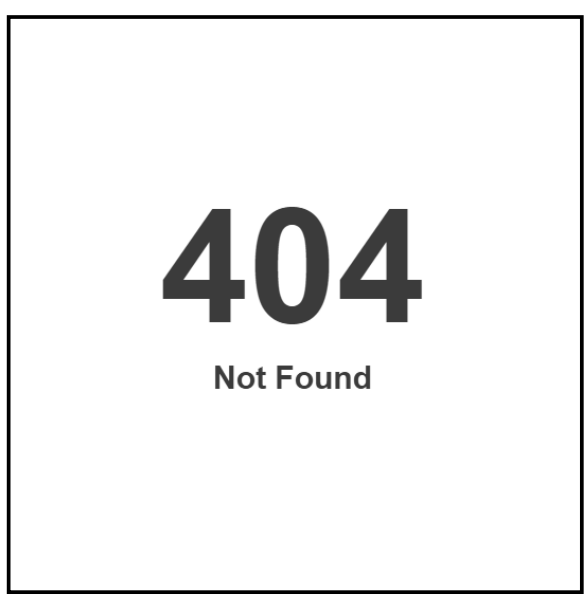

Keywords: Poverty, Immigration poem seeks to encourage the reader to reconsider our pre-conceived notions of an (un)documented, impoverished Canadian-Caribbean individual.

Similarly, this poem challenges the notion that to exist, is contingent on external perceptions. A tree in the Northwest Territories may exist unknowingly to us and still be able to blow gracefully in the wind.

\section{B I O}

Abigail is a hardworking and compassionate student that aims to bring awareness of health inequities in marginalized populations through advocacy. She is currently an undergraduate student at the University of Toronto studying both Neuroscience and Health Policy. 
I don't exist on paper

I'm telling you, it's true If you look up my records you'll find another you

I don't have the ability to grow

To compound like wealth

But instead, I slither

between fear and no health

I don't exist on paper

What don't you understand?

It sounds a bit odd

but it's all a part of the plan.

The numbers don't make sense or simply add up

But when you see me in person

You would never guess.

You'd say my smile is contagious

You'd say my skin is bliss

You'd say my ambition is inspiring

You'd say, I was born to be rich

I don't exist on paper

So how can I be free?

If you didn't get it by now,

This is my story of living in poverty 